УДК 624.21

ФУНКЦІЯ ІНТЕНСИВНОСТІ ВІДМОВ ЕЛЕМЕНТІВ СПОРУД

Асп. О. О. Давиденко (НТУ)

ФУНКЦИЯ ИНТЕНСИВНОСТИ ОТКАЗОВ ЭЛЕМЕНТОВ СООРУЖЕНИЙ

Асп. А. А. Давыденко (НТУ)

THE HAZARD RATE FUNCTION OF ELEMENTS STRUCTURES

\title{
Graduate student A. A. Davydenko
}

Стаття присвячена аналізу теоретичних засад оиінки інтенсивності відмов елементів споруд протягом часу життєвого ичиклу експлуатації. Аналізуються функиіі розподілу часу служби, якими можливо подати функиію інтенсивності відмов, адекватну історичним даним експлуатації залізобетонних мостів України. Пропонуються моделі, основані на прийнятих у теорії споруд розподілах випадкових змінних.

Ключові слова: інтенсивність відмов, імовірність відмови, надійність у функиії часу, U-подібна крива.

Статья посвящена анализу теоретических основ оченки интенсивности отказов элементов сооружений в течение времени жизненного ицила эксплуатации. Анализируются функции распределения времени службы, которыми возможно представить функцию интенсивности отказов, адекватную историческим данным эксплуатации железобетонных мостов Украины. Предлагаются модели, основанные на принятых в теории сооружений распределениях случайных переменных.

Ключевые слова: интенсивность отказов, вероятность отказа, надежность в функции времени, U-подобная кривая.

The article analyzes the theoretical basis assess the hazard rate of elements constructions during the time of life cycle exploitation. The problem became especially actual for Ukraine in the last 20-25 years. Today we must note a rapid growth physically obsolete structures, excessive increase in the number of bridges in need of repair, lack of survey data. In these circumstances, for trouble-free operation and life extension works, we need new scientific approaches to assess and prediction their technical condition lifecycle. Looking realistic efficient algorithms that would give the quantitative criteria of reliability and prediction resource elements in the function of time. Analyzes the distribution function of the time life may present function hazard rate adequate historical data maintenance service Ukraine reinforced concrete bridges. We offer models based on accepted theory works distributed random variables.

Keywords: hazard rate, failure rate, time-dependent reliability, bathtube curve.

Вступ. Статтю присвячено проблемі ймовірнісного моделювання відмови елементів споруд, в інших термінах оцінці залишкового ресурсу споруд. Проблема стала особливо актуальною для України в останні 20-25 років. Сьогодні доводиться констатувати стрімке збільшення кількості фізично застарілих споруд, непомірне зростання кількості мостів, що потребують ремонту, брак даних обстежень. У цих умовах для безаварійної експлуатації та продовження ресурсу 
споруд потрібні нові наукові підходи 3 оцінки i прогнозу їх технічного стану протягом життєвого циклу експлуатації. Потрібні ефективні реалістичні алгоритми, котрі дали б кількісні критерії рівня надійності та прогнозу ресурсу елементів у функції часу.

Аналіз останніх досліджень і публікацій. У сучасній теорії надійності поняття «функиія інтенсивності відмов» сьогодні $\epsilon$ класичним і вводиться як ще одна міра надійності у функції часу [8, 12]. Тут кількісною мірою надійності, параметром надійності, виступає ймовірність того, що відмова елемента споруди не відбудеться протягом часу експлуатаиіï [5, 7, 9-11]. В інших термінах - це функція часу, яка дає аналітичну залежність зростання ймовірності відмови протягом життєвого циклу експлуатації.

Поняття «функція інтенсивності відмов» відоме давно, застосовувалось уже на початку минулого сторіччя в багатьох сферах, починаючи 3 електротехнічних пристроїв або медичних прогнозів до соціальних проблем, наприклад у такій екзотичній задачі, як «прогноз часу повернення рецидивіста до тюрми». Проте в оцінці надійності конструкцій термін уперше 3'являється в аеронавтиці США тільки в 50-х роках [6].

У російській технічній літературі поняття «функція інтенсивності відмов» фігурує в монографіях В. В. Болотіна [1] (1971 р.) та [2] (1982 р.), С.С. Вентцель [3] (1972 p). Типовий графік функції інтенсивності відмов наведено в монографіях Болотіна В. В. [1, 2]. Цей символічний графік (рис. 1) має три характерних відтинки:

- відносно невеликий відтинок часу $t_{0}$, так званий період «пристосування» системи, коли інтенсивність відмов зменшується до приблизно постійного значення;

- центральний великий відтинок часу $t_{1}-t_{0}$, що відповідає практично всьому життєвому циклу безпечної експлуатації, характерний приблизно постійним значенням функції інтенсивності відмов;

- нарешті, невеликий кінцевий відтинок часу $t_{2}-t_{1}$ різкого збільшення значення функції інтенсивності відмов, тобто збільшення ризику відмови системи.

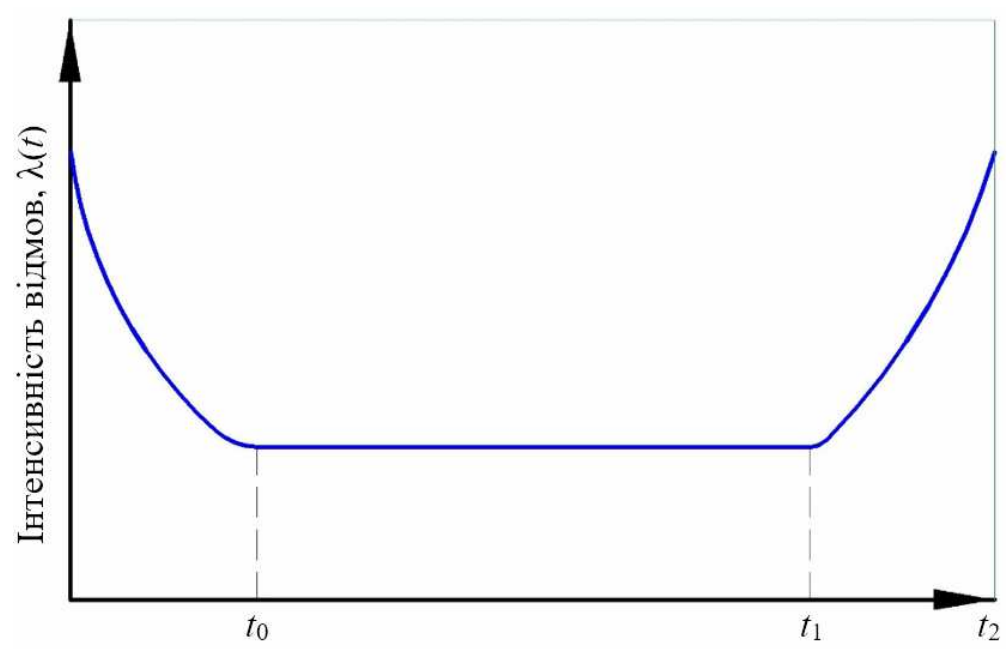

Рис. 1. Типова крива функції інтенсивності відмов $[1,2]$

Подібний вид мають криві функції інтенсивності відмов у класичних зарубіжних монографіях 3 надійності систем $[5,9,10,12]$. В англомовній літературі крива має усталену назву - «Uподібна крива» (bathtube curve). 
Виконаний аналіз великої кількості публікацій 3 проблеми дає підстави стверджувати, що U-подібна крива функції інтенсивності відмов, наведена В. В. Болотіним, характерна для технічних систем механічних, електричних, електронних тощо. Що стосується кривої для елементів будівельних конструкцій, то вона має дещо іншу форму, визначити яку саме і є завданням цього дослідження.

У літературі англійською, французькою, російською мовами ми не знайшли прикладу кривої функції інтенсивності відмов елементів споруд. Показово, що навіть у монографії В.В.Болотіна [1], яка має назву «Применение методов теории вероятностей и теории надежности в расчетах сооружений», не наведено ні одного прикладу кривої 3 числовими параметрами для елементів будівельних конструкцій.

Натомість є публікації, у яких узагалі виключається 3 розгляду період пристосування, а сама крива апроксимується ламаною лінією 3 двох відтинків, як наприклад у монографіях [5, 10] (рис. 2), де показані графіки функції інтенсивності відмов для електричних та механічних систем.

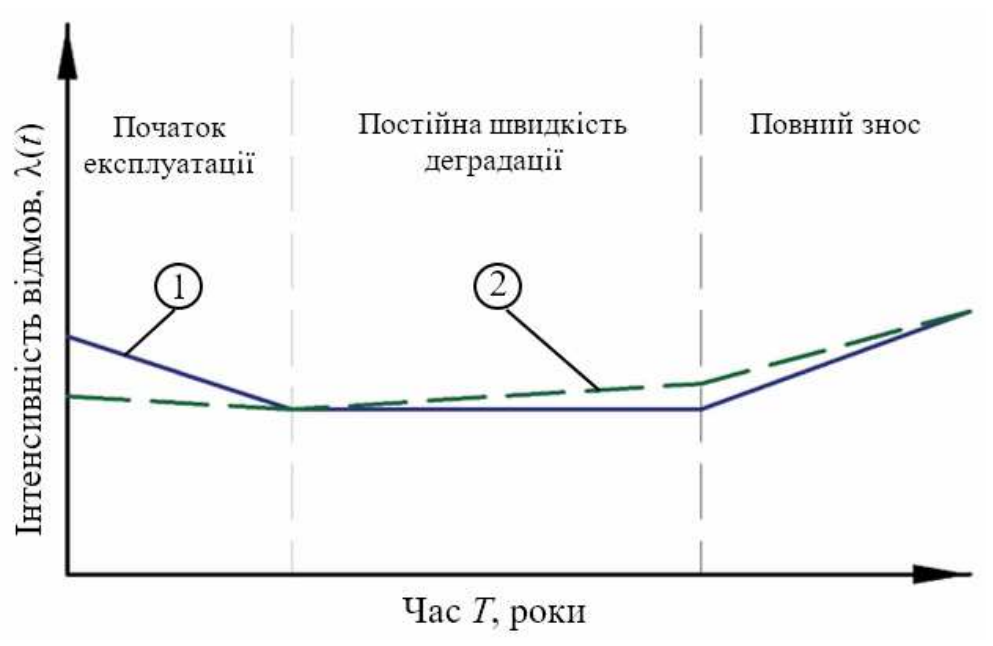

Рис. 2. Функції інтенсивності відмов для електричних та механічних систем [10]:

1 - функція інтенсивності відмов для електричних систем;

2 - функція інтенсивності відмов для механічних систем

Очевидно, що параметричні характеристики функції інтенсивності відмов $\epsilon$ ключом для коректного реалістичного прогнозу залишкового ресурсу елементів споруд. Нам необхідні теоретичні знання не тільки середньої інтенсивності відмов, а й визначення часу (періоду) життєвого циклу експлуатації, протягом якого інтенсивність відмов $\epsilon$ постійною. Для цього $є$ потреба у визначенні не тільки виду функції інтенсивності відмов, а також іiі числових параметрів. Ці і деякі супутні завдання дослідження вирішуються за моделлю, наведеною нижче.

Визначення мети та задачі досліджень. Метою роботи, поданої нижче, $\epsilon$ теоретичне дослідження інтенсивності відмов (швидкості деградації) у функції часу марковської моделі накопичення пошкоджень. Мотивацією дослідження $\epsilon$ принципова важливість цього єдиного керуючого параметра моделі в оцінці ресурсу елемента. 3 іншого боку, маємо констатувати, що в літературі бракує досліджень зміни параметра інтенсивності 
відмов у функції часу експлуатації елементів будівельних конструкцій. Для дослідження скористаємося сучасним підходом у теорії надійності у функції часу (time-dependent reliability), так званою «функиією інтенсивності відмов» (hazard function) [1-3, 5-12]. Дослідження обмежується залізобетонними елементами мостів.

\section{Основна частина дослідження.}

Скористаємося достатньо відомою сьогодні моделлю, теоретичні принципи якої наведено в монографіях [1-3, 8]. Тут ми наведемо детальний виклад отримання формули функції. Введемо необхідні змінні та функції розподілу:

- $t$ - значення випадкової змінної часу;

- $f(t)$ - щільність розподілу часу;

- $f(t) d t$ - ймовірність відмови на відтинку $[t, t+d t]$;

- $F_{T}(t)$ - інтегральна функція часу на відтинку $[0, t]$

$$
F_{\mathrm{T}}=\int_{0}^{t} f(\tau) d \tau=P(T \leq t),
$$

де $T$ - очікуваний час життєвого циклу експлуатації; $P$ - імовірність;

$-R(t) \quad$ - функція надійності імовірність того, що не відбудеться відмова на відтинку $[0, t]$ :

$$
R_{T}=\int_{t}^{\infty} f(\tau) d \tau=P(T>t)
$$

Визначення надійності протягом життєвого циклу експлуатації обертається навколо ідеї, що час служби елемента, тобто час до відмови (це еквівалентні поняття), $\epsilon$ випадковою величиною i iii значення описується інтегральною функцією розподілу (1) та щільністю ймовірності життєвого циклу експлуатації в термінах часу:

$$
f(t)=\frac{d}{d t}\left[F_{T}(t)\right]
$$

Очікуваний час життєвого циклу $T$ виражається як інтеграл від функції надійності $[3,12]$ :

$$
T=\int_{0}^{\infty} \tau f(\tau) d \tau=\int_{0}^{\infty} R(t) d t
$$

Тут, у залежності (4), другий інтеграл отримано шляхом інтегрування першого по частинах.

Інтенсивність відмов $\epsilon$ мірою того, як імовірність відмови змінюється в залежності від часу. Імовірність відмови в будь-якому заданому інтервалі $[t, t+\delta t] \epsilon$ ймовірність того, що час життєвого циклу $T$ міститься в заданому інтервалі

$$
P(t<T \leq t+\delta t)=F(t+\delta t)-F(t)=R(t)-R(t+\delta t) .
$$

Зауважимо, що вираз $\left[R\left(t_{1}\right)-R\left(t_{2}\right)\right] \epsilon$ еквівалентом $\left[F\left(t_{2}\right)-F\left(t_{1}\right)\right]$.

Аналітично параметр умовної ймовірності $\lambda(t)$ відмови може бути інтерпретованим як миттєва частота відмов

$$
\begin{gathered}
\lambda(t) \cdot \delta t \approx \mathrm{P}(T \leq t+\delta \mathrm{t} \mid T>t) . \quad \text { (6) } \quad \text { відмова на відтинку }[0, t]: \\
\lambda(t)=\lim _{\delta t \rightarrow 0} \frac{P(t<T \leq t)+\delta t}{\delta t P(T>t)}=\frac{f(t)}{R_{T}(t)}=\frac{f(t)}{1-F(t)} .
\end{gathered}
$$

Таким чином, функція інтенсивності відмов подається як відношення ймовірності відмови на відтинку $[t, t+\delta t]$ до ймовірності того, що не відбудеться 
3 викладеного можна бачити, що чотири функції $f(t), F(t), R(t)$ та $\lambda(t)$, які залучаються до визначення інтенсивності відмов, аналітично зв'язані між собою. Три 3 цих типових співвідношень наводяться нижче.

$$
\begin{gathered}
\lambda(t)=\frac{f(t)}{R_{T}(t)}=\frac{f(t)}{1-F(t)} . \\
f(t)=\frac{d F(t)}{d t}=\frac{d[1-R(t)]}{d t}=-R^{\prime}(t) . \\
\lambda(t)=-\frac{R^{\prime}(t)}{R(t)}=-\frac{d \ln R(t)}{d t} .
\end{gathered}
$$

Аналізуються функції розподілу часу служби, якими можливо подати функцію інтенсивності відмов, адекватну історичним даним експлуатації залізобетонних мостів України. Для аналізу прийнято три типи розподілів: нормальний, логістичний та Вейбулла (табл. 1). Нормальний та логістичний закони розподілу добре відомі в теорії споруд, традиційно застосовуються в аналізі надійності будівельних конструкцій. Що стосується закону розподілу Вейбулла, то він, як правило, застосовується для специфічних задач теорії ризиків - задачі розбудови функції інтенсивності відмов у тому числі $[3,7]$.

Вважається, що найбільш адекватним розподілом часу очікування в кожному стані, який дає можливість включити до розгляду ефекти природного старіння елемента, $\epsilon$ саме розподіл Вейбулла. Інтегральна функція двопараметричного розподілу Вейбулла задається виразом

$$
F(t)=1-\exp \left[-(\Psi t)^{\varphi}\right]
$$

і щільність імовірності (диференціальна функція розподілу) - виразом

$$
f(t)=\Psi \varphi(\Psi t)^{\varphi-1} \exp \left[(\Psi t)^{\varphi}\right]
$$

де $\Psi$ - коефіцієнт масштабу, $\Psi>0$;

$\varphi$ - коефіцієнт форми; $\varphi>1$ - випадок зростання інтенсивності відмов з часом.

Коефіцієнти визначаються через середні значення $\mu$ та середньоквадратичне відхилення $\sigma$.

Внесемо залежності (11) та (12) у формулу (7) i отримаємо функцію інтенсивності відмов, у якій час очікування подано розподілом Вейбулла

$$
\lambda \mathrm{w}(t)=\frac{\psi \varphi(\psi t)^{\varphi-1} \exp (-\psi t)^{\varphi}}{\exp (-\psi t)^{\varphi}}=\psi \varphi(\psi t)^{\varphi-1}
$$

Звід моделей, що розглядаються, наведено в табл. 1.

Порівняльний аналіз моделей (14) (16) показав, що дві з них - 3 нормальним розподілом часу (формула (14)) та розподілом Вейбулла (формула (16)) $\epsilon$ досить близькими за параметром інтенсивності відмови на відтинку часу [0 50] років. (Вид кривих «інтенсивність відмови - час» показано на рис. 3,4$)$.
Порівняння моделей (14) i (16) між собою приводить до висновку, що модель за нормальним розподілом часу $є$ більш реалістичною, має кращу збіжність 3 натурними даними статистичного аналізу історії експлуатації автодорожніх мостів України.

Модель за логістичним розподілом дає гірші результати, як видно з рис. 3,4 i табл. 2. 
Моделі визначення інтенсивності відмов

\begin{tabular}{|l|c|}
\hline \multicolumn{1}{|c|}{ Тип розподілу } & Модель визначення інтенсивності відмов \\
\hline Нормальний & $\lambda \operatorname{norm}(t)=\frac{\frac{1}{\sigma \sqrt{2 \pi}} \exp \left(-\frac{(t-\mu)^{2}}{2 \sigma^{2}}\right)}{1-\frac{1}{\sigma \sqrt{2 \pi}} \int_{-\infty}^{t} \exp \left(-\frac{(t-\mu)^{2}}{2 \sigma^{2}}\right) d t}$ \\
\hline Логістичний & $\lambda \operatorname{logis}(t)=\frac{1}{\sigma\left(1+\exp \left(\frac{-(t-\mu)}{\sigma}\right)\right)}$ \\
\hline Вейбулла & $\lambda \mathrm{w}(t)=\psi(15)$ \\
\hline
\end{tabular}

Порівняння результатів обчислення інтенсивності відмов 3 отриманими при статистичному аналізі [4] натурними даними

\begin{tabular}{|c|c|c|c|c|c|c|}
\hline \multirow{2}{*}{$\begin{array}{c}\text { Натурні } \\
\text { дані }\end{array}$} & \multicolumn{2}{|c|}{$\begin{array}{c}\text { Нормальний } \\
\text { розподіл }\end{array}$} & \multicolumn{2}{c|}{$\begin{array}{c}\text { Логістичний } \\
\text { розподіл }\end{array}$} & \multicolumn{2}{c|}{$\begin{array}{c}\text { Розподіл } \\
\text { Вейбулла }\end{array}$} \\
\cline { 2 - 7 } & $\begin{array}{c}\text { Іненсив- } \\
\text { ність }\end{array}$ & Відхилення & $\begin{array}{c}\text { Інтенсив- } \\
\text { ність }\end{array}$ & Відхилення & $\begin{array}{c}\text { Інтенсив- } \\
\text { ність }\end{array}$ & Відхилення \\
\hline 0,028 & 0,015 & 46 & 0,014 & 50 & 0,028 & 0 \\
\hline 0,030 & 0,03 & 0 & 0,022 & 27 & 0,039 & -30 \\
\hline 0,036 & 0,039 & -8 & 0,025 & 31 & 0,044 & -22 \\
\hline 0,042 & 0,044 & -5 & 0,028 & 33 & 0,048 & -14 \\
\hline
\end{tabular}

Висновки. Виконане теоретичне дослідження інтенсивності відмов (швидкості деградації) у функції часу марковської моделі накопичення пошкоджень дає можливість уточнення прогнозу життєвого циклу експлуатації. Прогнозування залишкового ресурсу залізобетонних елементів мостів за встановленими інтенсивностями відмов дасть більш реалістичні результати.

Прогнозування життєвого циклу із застосуванням моделі інтенсивності відмов привносить у марковську модель історичний досвід експлуатації мостів.
Дослідження нашої роботи, що базується на натурних даних з експлуатації залізобетонних, мостів легко узагальнюється на всі типи будівельних конструкцій.

Цим дослідженням доведено, що крива інтенсивності відмов протягом життєвого циклу монотонно зростає, у ній немає відтинку «пристосування елемента».

Ця робота була виконана під керівництвом д-ра техн. наук, професора Лантуха-Лященко А. I. Висловлюю йому мою щиру подяку. 


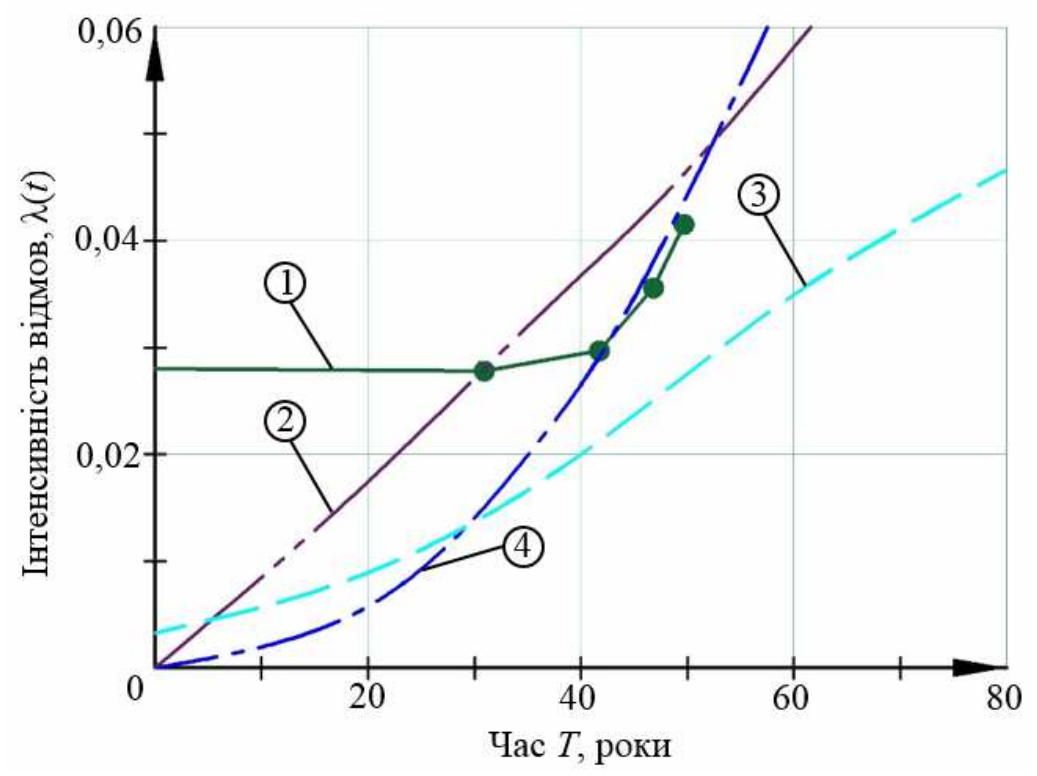

Рис. 3. Криві «інтенсивність відмови - час»:

1 - за натурними даними $\lambda \boldsymbol{T}(\boldsymbol{t})$;

2 - за функцією Вейбулла $\lambda \mathbf{w}(t)$ розподілу часу;

3 - за логістичною функцією $\lambda \operatorname{logis}(t)$ розподілу часу;

4 - за нормальною функцією $\lambda \operatorname{norm}(t)$ розподілу часу

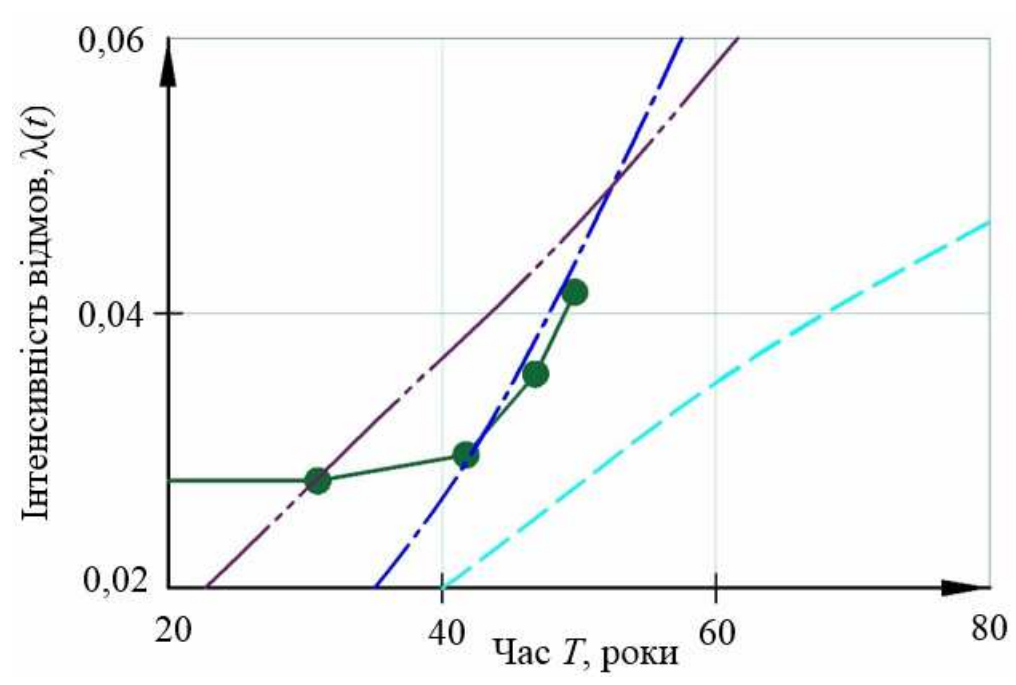

Рис. 4. Криві «інтенсивність відмови - час» на відтинку $t=20-80$ та $\lambda=0,02-0,06$

\section{Список використаних джерел}

1. Болотин, В. В. Применение методов теории вероятностей и теории надежности в расчетах сооружений [Текст] / В.В. Болотин. - М.: Стройиздат, 1971. - 255 с.

2. Болотин, В. В. Прогнозирование ресурса машин и конструкций [Текст] / В.В. Болотин. - М.: Машиностроение, 1984. - 312 с. 
3. Вентцель, Е. С. Исследование операций [Текст] / Е.С. Вентцель. - М.: Советское радио, 1972. $-552 \mathrm{c.}$

4. Давиденко, О. О. Моніторинг безпечної експлуатації автодорожніх мостів України [Текст] / О.О. Давиденко // Мости та тунелі: теорія, дослідження, практика: зб. наук. праць. Дніпропетровськ, 2015. - Вип. 7. - С. 4-12.

5. Alfredo Hua-Sing Ang, Wilson H. Tang. Probability Concepts in Engineering Planning and Design: Decision, Risk and Reliability. Volume II [Text] / John Wiley and Sons, New York. 1984. $-574 \mathrm{p}$.

6. Enright, M.P. Frangopol, D.M. Failure Time Prediction of Deteriorating Fail-Safe Structures [Text] / Enright, M.P. Frangopol, D.M. // Journal of Structural Engineering. - 1998. №124(12) - P.1448-1457.

7. Leemis, L.M. Reliability, Probabilistic Models and Statistical Methods [Text] /Prentice Hall, NJ. 1995. - 288 p.

8. Melchers, R.E. Structural Reliability Analyses and Prediction [Text] / Second Edition. John Wiley \& Sons, New York. - 1999. - 437 p.

9. NG, S-K., Moses F. Prediction of bridge service life using time-dependent reliability analysis [Text] / NG, S-K., Moses F. // Bridge management 3. Inspection, maintenance and repair. Papers presented at the third international conference on bridge management, university of surrey, Guildford, UK, 14-17 april. - 1996. - P. 26-33.

10. Patev, R.C. Introduction to Engineering Reliability [Електронний ресурс]. - Режим доступу: http://www.palisade.com/downloads/pdf/EngineeringReliabilityConcepts.pdf.

11. Mauricio Sánchez-Silva, Georgia-Ann Klutke. Reliability and Life-Cycle Analysis of Deteriorating Systems [Text] / Springer Series in Reliability Engineering. - 2016. - 355 p.

12. Thoft-Christensen, P. and Baker, M.J. Structural Reliability Theory and Its Applications [Text] / Springer-Verlag Berlin Heidelberg. - 1982. - 268 p.

Давиденко Олександр Олександрович, аспірант, асистент кафедри мостів та тунелів Національного транспортного університету. Тел. (050) 471-33-99. E-mail: aleksandros.davydenko@gmail.com. orcid.org/00000003-0176-3256.

Davydenko Aleksandr, graduate student, Department of Bridge and Tunnel Engineering, National Transport University. Tel. (050) 471-33-99. E-mail: aleksandros.davydenko@gmail.com. orcid.org/0000-0003-0176-3256.

Стаття прийнята 22.02.2017 р. 